\title{
Experimental Research for the Application of Mining Waste in the Trench Cutting Remixing Deep Wall Method
}

\author{
Yan Chao, Liu Songyu, and Deng Yongfeng \\ Institute of Geotechnical Engineering, Southeast University, Nanjing 210096, China \\ Correspondence should be addressed to Yan Chao; yanchao@seu.edu.cn
}

Received 1 December 2014; Accepted 18 January 2015

Academic Editor: Charles C. Sorrell

Copyright ( 2015 Yan Chao et al. This is an open access article distributed under the Creative Commons Attribution License, which permits unrestricted use, distribution, and reproduction in any medium, provided the original work is properly cited.

\begin{abstract}
This paper focuses on the use of fly ash (FA) or ground granulated blast slag (GGBS) and reactive lime blends for cement-stabilized Nanjing clay, comparing them with Portland cement (PC) for enhanced technical performance. A range of tests were conducted to investigate the properties of stabilized soils, including macrostrength (UCS), permeability, and microstructure analyses by scanning electron microscopy (SEM). The influence of PC: (FA + lime) ratio, PC: (GGBS + lime) ratio and curing time was addressed. The UCS and permeability results revealed that PC-FA-lime was more efficient than PC-GGBS-lime as a binder for soil stabilization, with an optimum proportion of PC: $(\mathrm{FA}+$ lime $)=3: 7$ at $25 \%$ binder content, varying with curing time. The microstructure analysis reveals that fly ash mainly changes the pore volume distribution, which ranges between $0.01 \mu \mathrm{m}$ and $1 \mu \mathrm{m}$, and produces more $\mathrm{CSH} / \mathrm{CASH}$ bonding and fissures due to the secondary hydration and pozzolanic reactions. Based on the favourable results obtained, it can be concluded that the soft soils can be successfully stabilized by the combined action of cement, fly ash, and lime. Since fly ash is much cheaper than cement, the addition of fly ash and lime in cement-soil mix may particularly become attractive and can result in cost reduction of construction.
\end{abstract}

\section{Introduction}

More recently, cement soil stabilization to construct vertical barriers, including deep mixing method (DMM) and the trench remixing and deep wall method (TRD) have found increased usage. An advantage of these techniques was that a high strength can be achieved, making Portland cement (PC) the most commonly used binder in soil stabilization $[1,2]$. The unconfined compressive strength (UCS) and the permeability of PC stabilized soils were the key design parameters in the design of cut-off walls to prevent seepage in water-retaining structures, which have been extensively researched [3]. To reduce the stabilization cost, the incorporation of industrial byproducts in partial or full cement replacement, such as fly ash (FA), ground granulated blast furnace slag (GGBS), has been extensively applied in practice $[4,5]$. Fly ash or GGBS used on its own shows a slow hydration rate, resulting in a low early strength, and hence the fly ash or GGBS hydration is usually accelerated by activator [6-8]. Since the use of lime for soil stabilization has a long history and been successfully employed in many countries [9-13], the incorporation of lime with fly ash or GGBS is easily accepted for geotechnical applications.

It was found that high-volume fly ash pastes underwent a lower degree of fly ash reaction, and in the pastes with $45 \%$ to $55 \%$ fly ash, more than $80 \%$ of the fly ash still remained unreacted after 90 days of curing [14]. Ratios of cement : fly ash of $1: 2$ with $22 \%$ binder content were reported as being suitable for reducing the permeability [15]. In the grout studied, fly ash was used to replace $30 \%$ by mass of cement [16]. For soft soil in the Minjiang estuary, results from scanning electron microscopy (SEM) and UCS suggested that the intensity of stabilized soil is the largest by using the stabilizer composed of $16 \%$ cement mixing ratio and $40 \%$ fly ash mixing amount [17]. Zhang suggested that, as most of the ash particles remain unreacted even after a long period of curing, high-volume fly ash pastes can be considered as a composite material with the ash particles serving as reactive microaggregates [18].

Tasong et al., Wild et al. observed that the lime-activated GGBS hydration was much more rapid than that of the pozzolanic reaction of lime with clay. SEM and XRD analysis 
TABle 1: Physical properties of clay.

\begin{tabular}{lccccccc}
\hline $\begin{array}{l}\text { Natural water } \\
\text { content }(\%)\end{array}$ & $\begin{array}{c}\text { Wet density } \\
\left(\mathrm{kN} / \mathrm{m}^{3}\right)\end{array}$ & Void ratio $e$ & \multicolumn{2}{c}{ Particle size distribution $(\%)$} & Liquid limits $W_{L}(\%)$ & Plastic limits $W_{P}(\%)$ \\
\hline 35 & 16.8 & 1.21 & 5.4 & 13.8 & 80.8 & 48.7 \\
\hline
\end{tabular}

suggested that, due to its high alumina and silica content, a complex C-A-S-H gel intermixed with hydrotalcite-type phases containing magnesium are the main reaction products of GGBS-lime stabilized clay [19-21]. Macphee et al. found that the hydraulic reactions of GGBS have a "pore-blocking" effect which leads to a greater ultimate strength and lower permeability [22].

However, it should be noted that although hydration characteristics of fly ash (or GGBS) are common for all PC-fly ash-lime (or PC-GGBS-lime) systems, there are substantial differences between low-volume and high-volume (above $50 \%$ by weight) PC-fly ash-lime (or PC-GGBS-lime) systems. A more quantitative understanding of the systems hydration process with different levels of replacements is needed.

Hence, this study investigates the strength and microstructure evolution of PC-fly ash-lime (or PC-GGBS-lime) with a number of PC: fly ash:lime (or PC:GGBS:lime) ratios for soil stabilization. A range of tests were conducted to investigate the performance of stabilized soils, including UCS, permeability, scanning electronic microscopy (SEM), and mercury intrusion porosimetry (MIP). The influence of PC: fly ash (or GGBS): lime ratio, curing period were considered.

\section{Materials and Testing Methods}

2.1. Soils, Binders and Sample Preparation. The specimens were prepared with clay obtained from the Nanjing area, located in Jiangsu, China. The basic properties of the selected soil samples are listed in Table 1 and it was characterized as a lean clay (CL) by the USCS (Unified Soils Classification System, ASTM D2487-11) [23]. Note that the clay mineral was the main component and the content of the interstratified illite/smectite was over $80 \%$.

Table 2 presents four different stabilizing agents which were used in the present study, namely, Ordinary portland cement, Class F fly ash, ground granulated blast furnace slag (GGBS) and lime. PC, type OPC 42.5 R/N (from Xuzhou Coal Mine Bureau, China) according to the European Cement Standard (EN197-1), specifies that the ratio of $\mathrm{CaO}$ to $\mathrm{SiO}_{2}$ should exceed 2.0 and the $\mathrm{MgO}$ content should not exceed $2.0 \%$. Fly ash, grade I class F, falled well within the guidelines of GB/T1596-2005 (from Xuzhou Power Plant, China). GGBS used in this investigation were collected from Nanjing Iron and steel plant and lime were procured from Nanjing Chemical Reagent Co., Ltd.. The fineness of fly ash was $11.6 \%$. The particle diameter of GGBS was distributed in the range of $0.5-$ $1 \mathrm{~mm}$.

There were three types of binder stabilized soils: PC stabilized clay (PCC), PC-fly ash-lime stabilized clay (PFLC), and PC-GGBS-lime stabilized clay (PGLC). Tests performed
TABLE 2: Chemical properties of the materials from suppliers' datasheets.

\begin{tabular}{|c|c|c|c|c|}
\hline Oxide content (\%) & OPC & Fly ash & GGBS & Lime \\
\hline $\mathrm{SiO}_{2}$ & 20.9 & 51.4 & 33.6 & 0.36 \\
\hline $\mathrm{Al}_{2} \mathrm{O}_{3}$ & 5.3 & 28.2 & 16.2 & 0.04 \\
\hline $\mathrm{CaO}$ & 65.8 & 5.8 & 39.2 & - \\
\hline $\mathrm{Fe}_{2} \mathrm{O}_{3}$ & 5.3 & 3.4 & 0.6 & 0.03 \\
\hline $\mathrm{SO}_{3}$ & 2.4 & 1.1 & 2.5 & - \\
\hline $\mathrm{MgO}$ & 1.0 & 1.3 & 8.1 & 0.23 \\
\hline $\mathrm{Na}_{2} \mathrm{O}$ & - & 0.9 & - & - \\
\hline $\mathrm{K}_{2} \mathrm{O}$ & - & 0.7 & - & - \\
\hline $\mathrm{MnO}$ & - & - & 0.2 & - \\
\hline $\mathrm{Ca}(\mathrm{OH})_{2}$ & - & - & - & 97.6 \\
\hline $\mathrm{CaCO}_{3}$ & - & - & - & 0.93 \\
\hline
\end{tabular}

included UCS, permeability, and microstructural analyses (for selected mixes). One binder contents, by weight of the wet soil and binder together, of $25 \%$, was used in all mixes, and all the mixes were tested for UCS at 7, 14, and 28 days, as well as for permeability at 7, 14, and 28 days. The testing program is shown in Table 3.

A relatively lower fly ash (or GGBS) : lime ratio could increase the early strength of stabilized soil, while it might also result in relatively low longer term strength by the decrease of fly ash (or GGBS) content. As reactive lime was currently more expensive than Fly Ash (or GGBS), a high lime content in the binder was not encouraged for economic reasons [24]. And the main purpose of this study was to meet impermeability, so a relatively lower lime : fly ash (or GGBS) ratio $15 \%$ was chosen for all samples.

Note that the PC content (mass content of cement to wet soil at $2.5 \%, 5 \%, 7.5 \%, 10 \%)$ was less than that adopted in most vertical barrier in Chinese TRD projects (usually 20\% 25\%) [25], considering the effectiveness and economy of the cement, while the high fly ash (or GGBS) content was applied (the ratio of cement mass to the total binders mass ranges from $10 \%$ to $40 \%$ ).

To prepare the testing samples, the selected clay in Nanjing area was first dried at $30^{\circ} \mathrm{C}$, and distilled water was then added until the water content arrived at 35\% (approximately the sample's natural water content). The wet soil were initially cured for one day, then the binders were added. The binders and the prepared soil were thoroughly mixed for 5 minutes.

The homogenized paste was then transferred into a cylindrical mould, which was of $50 \mathrm{~mm}$ in diameter and $100 \mathrm{~mm}$ high. To eliminate any air pocket, each layer was artificially compacted by vibration. The cemented soil samples were placed in a sealed plastic container at the $95 \%$ $\pm 3 \%$ humidity and $20 \pm 2^{\circ} \mathrm{C}$. After the first 24 hours of 
TABLE 3: Testing program.

\begin{tabular}{llccc}
\hline Mix & Soil & Binder & Cement content $(\%)$ & Testing \\
\hline PCC & Clay & PC & $25 \%$ & UCS at $7,14,28$ days \\
PFLC & Clay & PC $:($ FA + L $)=1: 9,2: 8,3: 7,4: 6$ & $2.5 \%, 5 \%, 7.5 \%, 10 \%$ & permeability at 7,14, and 28 days \\
PGLC & Clay & PC: $(\mathrm{G}+\mathrm{L})=1: 9,2: 8,3: 7,4: 6$ & $2.5 \%, 5 \%, 7.5 \%, 10 \%$ & microstructure (selected mixes) at 28 days \\
\hline
\end{tabular}

curing, they were demolded and placed back in the standard container for curing until ready for testing. Note that the detailed procedure for preparation of specimen was widely recommended for the cemented soft clay [26-29].

\subsection{Unconfined Compression Test and Permeability Test. The} average UCS values (three identical specimens) at a strain rate of $1 \mathrm{~mm} / \mathrm{min}$ for different mixes were determined. Two cylinders per mix proportion were subjected to permeability tests and the mean hydraulic conductivity ascertained.

Both ends of a sample were cut flat to within $0.05 \mathrm{~mm}$, and the height, diameter, and weight of the sample were measured before testing. The UCS was measured on a universal testing machine and was carried out in accordance with ASTM standard D1633-00 (ASTM 2007) [30].

Permeability testing was conducted in duplicate using a flexible-walled permeameter (ASTM D5084; ASTM 2003) [31]. For all samples, the cell pressure was preset as $450 \pm 2 \mathrm{kPa}$ and the seepage pressure as $350 \pm 2 \mathrm{kPa}$. Due to the very low values of hydraulic conductivity for cemented soils, the height of these samples was cut to $5 \mathrm{~cm}$ to reduce their seepage path.

2.3. Mercury Intrusion Porosimetry (MIP). MIP is a method used to determine the pore size distribution of porous materials based on the unique relationship between the intrusion pressure and equivalent pore diameter proposed by Washburn [32]:

$$
D=-\frac{4 \gamma \cos \theta}{P}
$$

where $D$ is pore diameter, $\gamma$ is surface tension of mercury, $\theta$ is contact angle, and $P$ is applied pressure. Note that the recommended contact angle of $140^{\circ} \mathrm{C}$ and the mercury surface tension of $0.480 \mathrm{~N} / \mathrm{m}$ were employed [33-35]. Because the range of intrusion pressure was $3.7 \mathrm{kPa}$ to $241.1 \mathrm{MPa}$ for the PoreMaster-60 (by Quantachrome Corporation USA), the pore sizes measured ranged from 0.005 to $340 \mu \mathrm{m}$. In this study, five samples (i.e., $25 \%$ cement without FA or GGBS, $2.5 \%$ cement with $22.5 \%$ FAL, $7.5 \%$ cement with $17.5 \%$ FAL, $7.5 \%$ cement with $17.5 \%$ GL, $10 \%$ cement with $15 \%$ GL after 28 days of curing) were tested.

The MIP samples were selected from the center of the crushed UCS samples. Small pieces of crushed samples were first trimmed to appropriate sizes and shapes and then soaked with acetone for 7 days to stop the hydration reactions. After 7 days, specimens were frozen at $-196^{\circ} \mathrm{C}$ by immersion in liquid nitrogen for $5 \mathrm{~min}$ and then were sublimated by sustaining in vacuum chamber of a freeze dryer for approximately 24 hours [34].

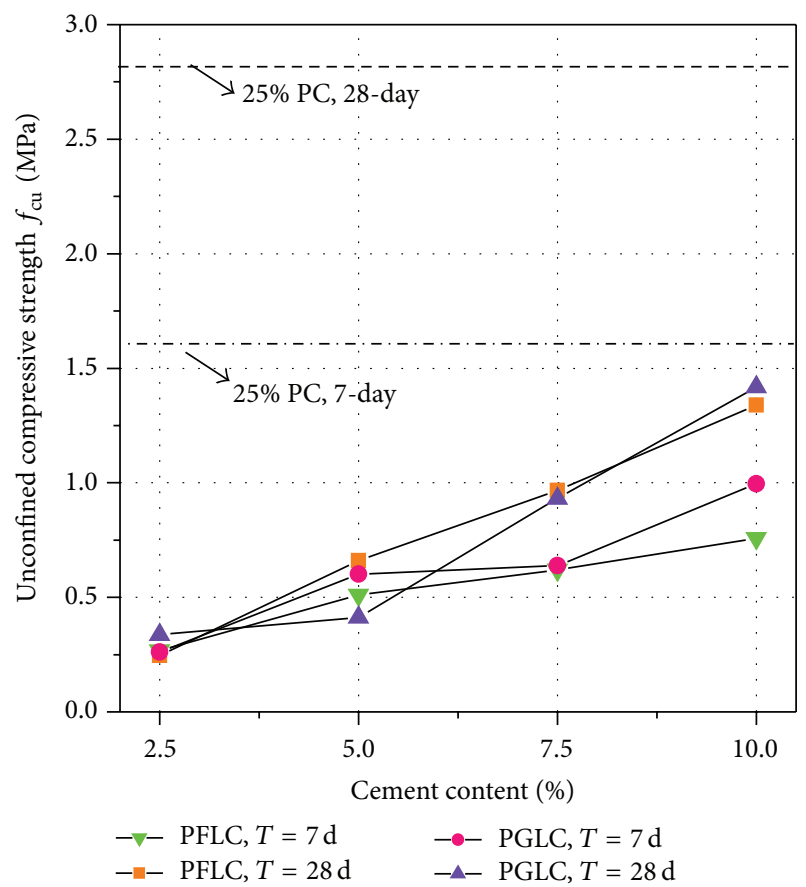

FIGURE 1: Relationship between $f_{\mathrm{cu}}(\mathrm{MPa})$ and cement contents (\%) of selected stabilized clay at $25 \%$ binder content.

2.4. Scanning Electronic Microscopy (SEM). Scanning electron microscopy was used to further investigate the microstructure changes of the cemented soils containing and mechanism. Five specimens (just like MIP) were scanned in this study.

The dried sample pieces not exceeding $10 \mathrm{~mm}$ in size were pretreated and lyophilized same as MIP test. Prior to examination, sample pieces were mounted on aluminium stubs using carbon tape and paste, and gold-coated in the thickness of $200-300 \AA(1 \AA=0.1 \mathrm{~nm})$ to induce electrically conductivity [36].

\section{Results and Discussions}

3.1. Mechanical Behaviors of Cement-Stabilized Samples Containing Fly Ash-Lime (or GGBS-Lime). The variation of stabilized soil strength with time is presented in Figure 1 compared with those of PC stabilized soils. The UCS of PFLC mixes and PGLC mixes increased with the increasing cement ratio and curing period. The same behavior was observed for both mixes.

For 7-day UCS of PFLC mixes (or PGLC mixes), the $\mathrm{PC}: \mathrm{FAL}=1: 9$ (or PC: $\mathrm{GL}=1: 9$ ) reached the lowest. So as 


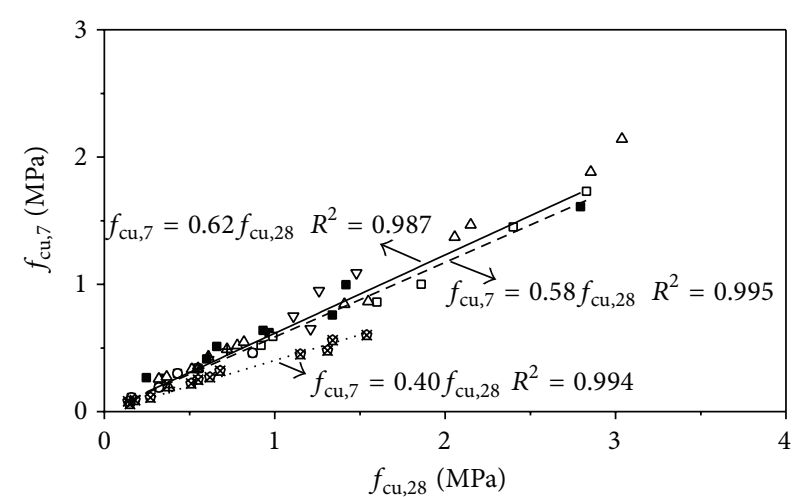

- Fly ash (GGBS) blended cement admixed Nanjing clay (this text)

- Cement admixed Ariake clay [37]

- Cement admixed Bangkok clay [37]

$\Delta$ Biomass ash blended cement admixed Bangkok clay [38]

$\nabla$ Cement admixed soft soil of one reach of the Yangtze River [39]

4 Cement admixed dark soil [40]

¿ Cement admixed LYG clay [41]

FIGURE 2: $f_{\mathrm{cu}, 7}$ versus $f_{\mathrm{cu}, 28}$ plot for different cement-treated clays.

28-day UCS. This was attributed to the facts that the lowest cement content of PC:FAL $=1: 9$ (or PC: $\mathrm{GL}=1: 9$ ) mixes and a relatively lower lime : fly ash (or GGBS) ratio 15\% was not the most rational ratio. It is consisted with the results of clayey silt by Yi et al. [24] who considered that the low lime content in the binder was not sufficient to activate the fly ash (or GGBS) to achieve high early strength.

For the 28-day UCS of the PFLC mixes and PGLC mixes in Figure 1, the UCS values reached much lower than those of the corresponding PC stabilized soils. However, The 28-day UCS of PFLC mixes and PGLC mixes with the $7.5 \%$ cement content closed to $1 \mathrm{MPa}$, which can meet the engineering requirements.

Considering that high content fly ash (or GGBS) was a type of special cemented soil, the empirical relationship of common cemented soils must be verified for this material. Figure 2 shows the $f_{\text {cu }}$ of cement-treated clay containing fly ash (or GGBS) and lime after 7 and 28 days of curing compared to that of Bangkok, Ariake, LYG clay and other soft soils using just ordinary Portland cement or slag-cement $[25,37-41]$. The linear fitting results are expressed as follows:

$$
f_{\mathrm{cu}, 7}=0.62 f_{\mathrm{cu}, 28} \text {. }
$$

Equation (2) indicates that the unconfined compression strength of the CFAL cemented soils after a curing period of 7 days is approximately 0.62 times that measured after 28 days of curing. This finding demonstrates that time-dependent strength prediction equation of PFALC (or PGLC) mixes stabilized clay is similar to the finding of other references [37]. Hence, the activity of PFAL (or PGL) can ensuring the early strength.

The secant modulus $\left(E_{50}\right)$, obtained from unconfined compression tests, is expressed as the ratio of the stress to strain when the axial stress is $50 \%$ of the unconfined compressive strength [42-47]. The relationship between the

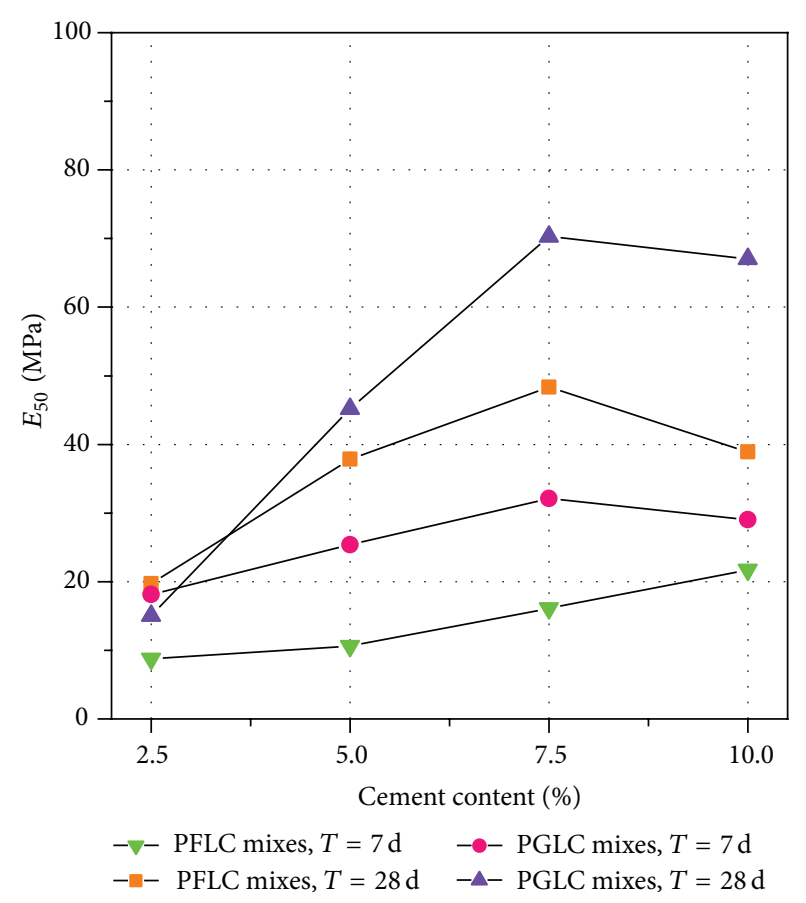

FIGURE 3: Relationship between $E_{50}(\mathrm{MPa})$ and cement contents (\%).

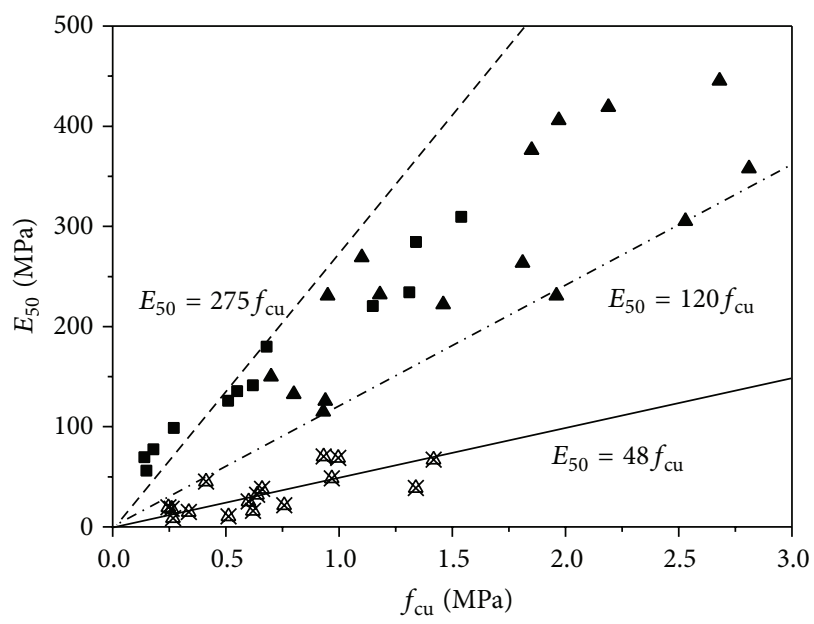

- LYG cement-clay [41]

- LYG cement-clay [48]

Fly ash (GGBS) and lime blended cement admixed Nanjing clay (this text)

FIGURE 4: Correlation of modulus of elasticity with compressive strength for the different mixes considered.

secant modulus and cement content is shown in Figure 3. The curve does not smooth when the cement content exceeds $7.5 \%$, which is slightly different to that of the unconfined compression strength in Figure 1. It can be stated that the higher cement content, the higher modulus of elasticity.

The relationship between the secant modulus and UCS of cement-treated clay containing fly ash (or GGBS) and lime from this study shown in Figure 4. The LYG clay mentioned in the Figure 4, a type of quaternary marine sedimentation, 


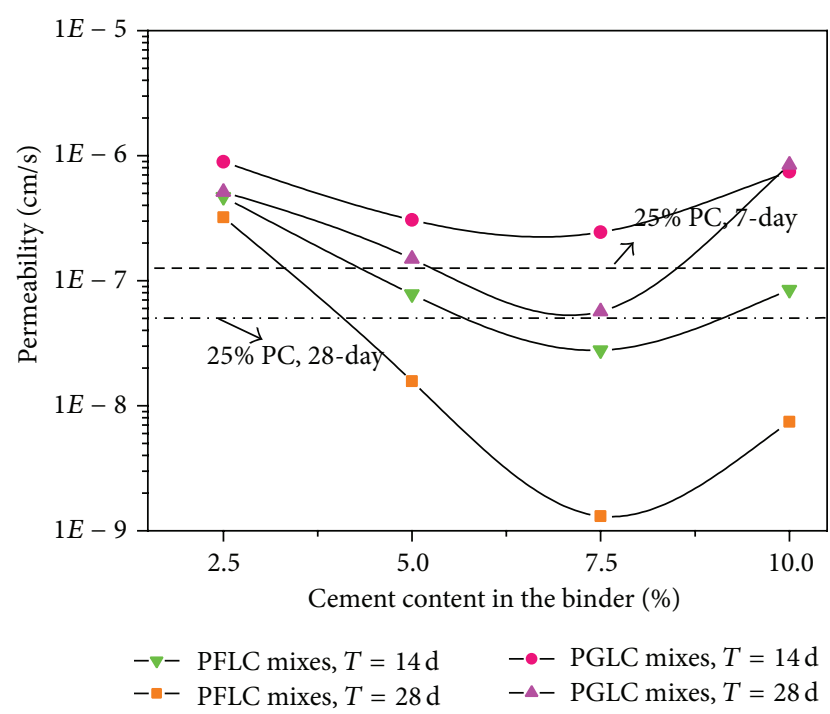

FIGURE 5: The 28-day permeability of stabilized clay.

is widely distributed in the eastern coastal areas of China. Figure 4 demonstrates that the $E_{50}$ of PFAL (or PGL) treated soil can be taken $E_{50}=48 q_{u}$.

In comparison to other common cement-treated soils reported in the literatures, Zhang et al. [41] and Zhang et al. [48] founded that the ratio ranged from 120 to 275 for Lianyungang clay (the same clay examined in both study) for cement contents ranging from $10 \%$ to $20 \%$. Lorenzo and Bergado [46] also reported that $E_{50}$ equals $147 q_{u}$ for Bangkok clay mixed with cement contents at $5 \%$ to $20 \%$.

Although the modulus of elasticity is proportional to the UCS of cement-treated soils, the results showed that the lower slope between the UCS and the $E_{50}$ are significant. It should be pointed out that the physicochemical properties and the origin (i.e., geological processes, etc.) of soils differ in various regions of the world (Zhang et al., 2013) [41].

3.2. Permeability. Figure 5 shows the 14-day and 28-day permeability values of the stabilized clay. The relationship of the permeability with the fly ash content in the binder exhibits a little different trend to that of the UCS, which demonstrating there is also an optimum PC: FAL ratio for lowest permeability.

The minimum permeability of PFLC mixes occur approximately at $7.5 \%$ cement contents $(\mathrm{PC}: \mathrm{FAL}=3: 7)$. Even with different curing times. The trend of 25\% PGLC mixes is similar to that of PFLC mixes, while the PFLC mixes have lower 28-day permeability than PGLC mixes at different PC : activator ratio. For 25\% binder content mixes, the PFLC mixes even yield lower 28-day permeability than the cementstabilized clay.

It is known that the hydration of cement is generally an expansive process, and the hydration products which include $\mathrm{CSH}$ and $\mathrm{CH}$ can fill the pores to decrease the permeability of cemented soil [24]. However, there is different behavior between the permeability and USC of stabilized soil. The specific reasons will be explained in SEM tests.
3.3. Micromechanism. Figure 6 shows the typical relationships between the mercury intrusion curves of samples containing $25 \%$ binder after 28 days of during the formation of cumulative intrusion volume $(\mathrm{mL} / \mathrm{g})$ and the log differential intrusion volume $(\mathrm{mL} / \mathrm{g})$.

The cumulative pore volume decreased when the PC:FAL ratio varied from 1:9 to 4:6 irrespective of the curing time. The total pore volume was minimised at a cement content from $5 \%$ to $10 \%$ (PC:FAL $=2: 8$, PC:FAL $=3: 7, \mathrm{PC}: \mathrm{FAL}=4: 6)$, which is probably attributed to the reasonable fly ash proportion for secondary hydration. The effect of the fly ash (or GGBS) content on the microstructure was further clarified in the log-differential intrusion volume analysis. In addition, this density clearly changed when the pore distribution ranged from $0.01 \mu \mathrm{m}$ to $1 \mu \mathrm{m}$. The micropore distribution was classified according to Horpibulsuk et al. $(2009,2010)[49,50]$ to further analyse the pore size distribution who counted the pore volume of pores that ranged among $0.01,0.1,1$, and $10 \mu \mathrm{m}$ in diameter, respectively.

Figure 7 shows the pore volume statistics calculated by the Horpibulsuk method (2010) [50]. The addition of FAL $(\mathrm{PC}: \mathrm{FAL}=3: 7)$ decreases the pore volume between $1 \mu \mathrm{m}$ and $>10 \mu \mathrm{m}$ of cemented soils after 28 days' curing but those $<0.01 \mu \mathrm{m}$ is on the contrary. The microvolume between $0.01 \mu \mathrm{m}$ and $0.1 \mu \mathrm{m}$ at $17.5 \% \mathrm{FAL}$ is almost identical to that measured at $0 \%$ FAL. Therefore, pore volume distribution between $0.1 \mu \mathrm{m}$ and $1 \mu \mathrm{m}$ affected the macrostrength but it is not the only main factor for cemented soils in this study. In other words, the cementation (or bonding) and fissures may constitute another key factor that affects the macrostrength.

The SEM micrographs which shown in Figure 8 for selected 28-day $25 \%$ binder stabilized soils: PC-alone, $P C: F A L=1: 9, P C: F A L=3: 7$ and PC $: G L=3: 7$. For the PCalone stabilized clay, Figures 8(a) and 8(b) displayed a dense surface morphology with soil particles well interconnected and pores well filled by PC hydration products (mainly CSH gel), explaining the high strength of 28-day PC stabilized clay.

However, the portlandite was absent in the PC:FAL $=1: 9$ mixes due to its consumption during the pozzolanic reaction of the natural pozzolanic material in the soil and activation fly ash. For the PC:FAL $=1: 9$ mixes stabilized clay, isolate soil and fly ash particles without interconnection was clearly seen in Figure 8, indicating the minimal hydration of fly ash took place without activator after 28 days of curing and hence resulted in stabilized soil with almost $0 \mathrm{MPa} 28$-day UCS.

Comparison of Figures 8(d) and 8(f) at 3000 times magnification preliminary shown that the netted structure of PC: FAL = 3:7 mixes was obviously denser. The possible hydraulic compounds that enwrap the soil aggregate can be empirically observed are products of the cement or fly ash hydration, these include, for example, various types of calcium silicate hydrate crystal $(\mathrm{CSH})$, calcium aluminium silicate hydrates like gismodine $\left(\mathrm{CaAl}_{2} \mathrm{Si}_{2} \mathrm{O}_{8} \cdot 4 \mathrm{H}_{2} \mathrm{O}\right)$, portlandite $\left(\mathrm{Ca}(\mathrm{OH})_{2}\right)$, and so forth. as well as products resulted of the reaction mainly of the $\mathrm{SiO}_{2}$ contained in clay with 

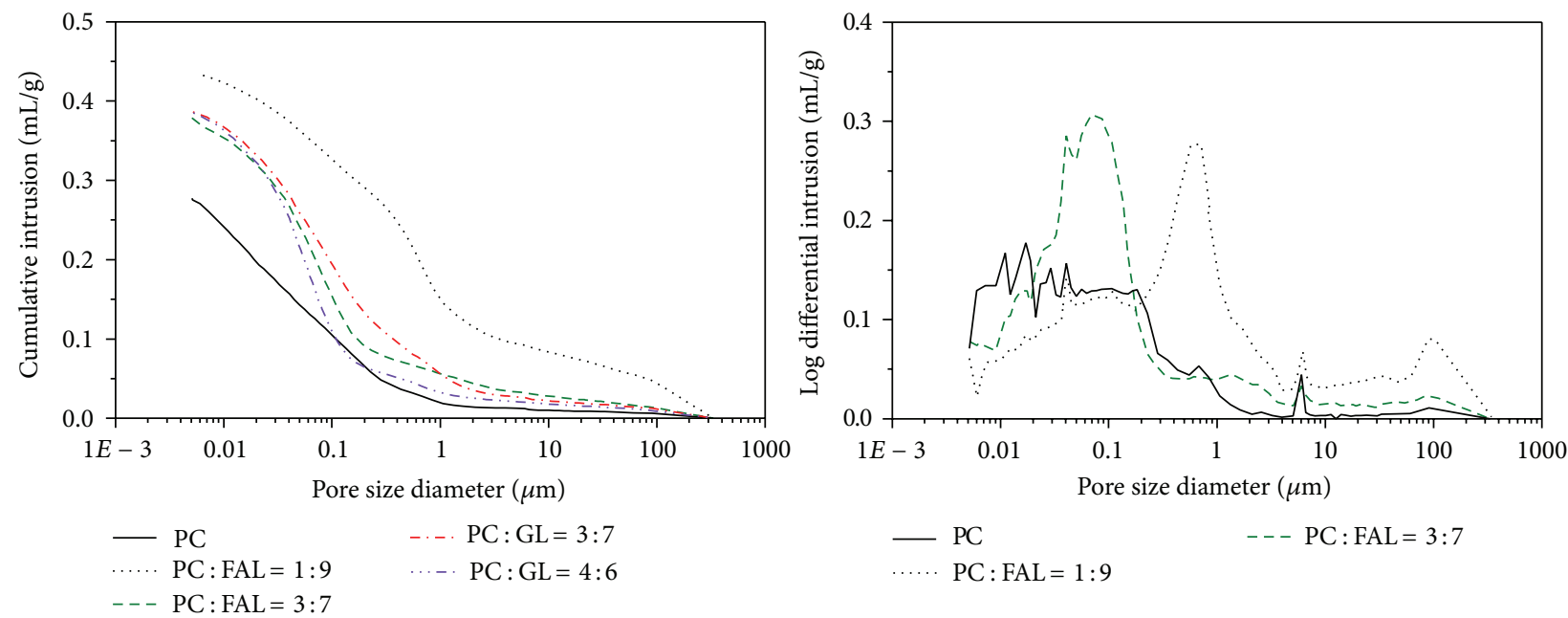

$\ldots$. PC: $\mathrm{FAL}=1: 9$
$--\mathrm{PC}: \mathrm{FAL}=3: 7$

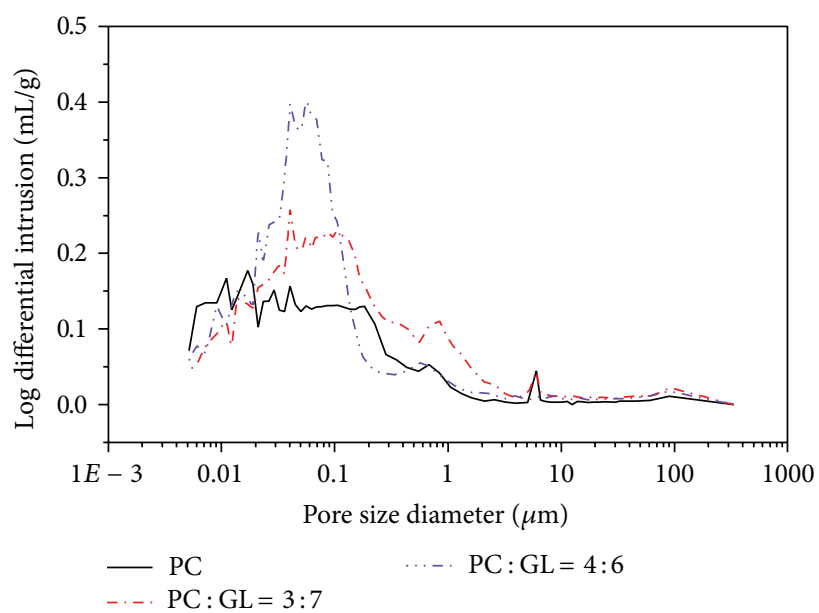

FiguRE 6: Cumulative mercury intrusion and log differential intrusion versus pore size diameter curve after 28 days of curing.

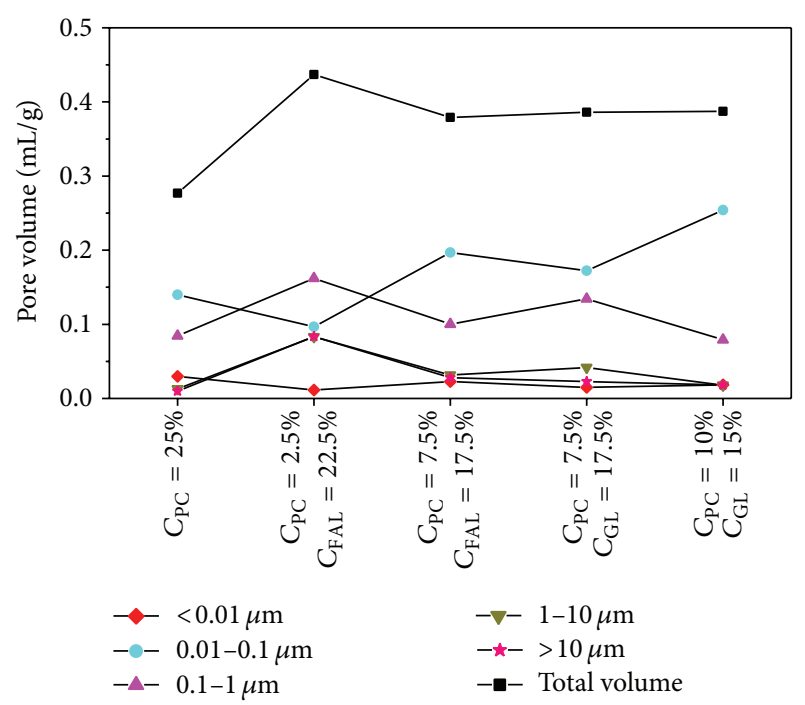

FIGURE 7: Pore size distribution classified by an order of magnitude of different proportion of stabilized clay. the portlandite released during the hydration of fly ash and cement [51].

The new products and reformation of the microstructure effectively decreased the permeability of stabilized soil. However, the strength development was limited due to the poorly reticulate and fibrous structure and weak bonding ability of particles.

The better permeability resistance ability of cement-fly ash-lime combination stabilized soil can be attributed to the pozzolanic properties of the mixture and to the utilization of readily available silica and alumina from fly ash by the calcium from the lime to generates the advantageous hydration products, which clogged pores between the soil aggregates.

Figure $8(\mathrm{~g})$ indicates that micropores of PGLC mixes can be filling with effectiveness. At 3000 times magnification, this indicates that the main hydration product of all the mixes was $\mathrm{CSH}$, consistent with Song et al. [7] and Yi et al. [24]. Meanwhile, since the particle size of GGBS was not small enough, the secondary hydration and pozzolanic reaction was not as effective as fly ash. 


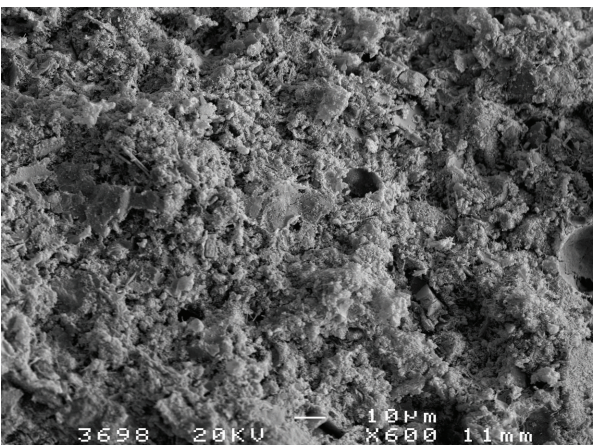

(a) PC 600 times

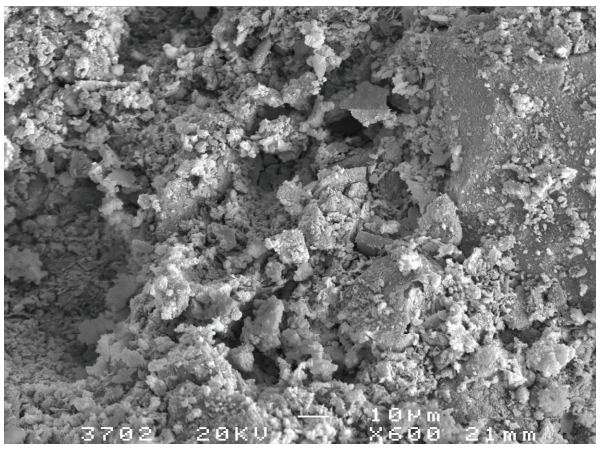

(c) PC:FAL $=1: 9600$ times

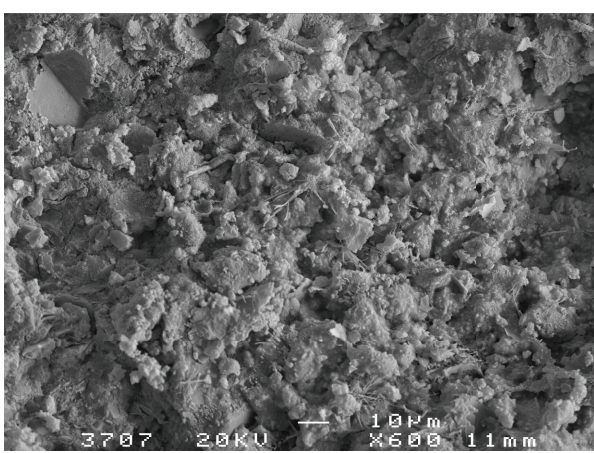

(e) PC:FAL $=3: 7600$ times

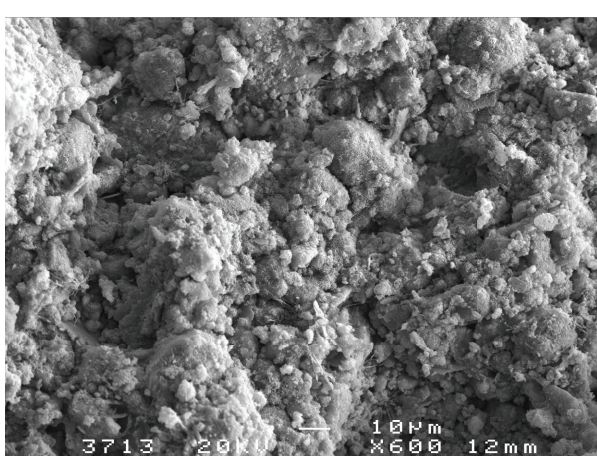

(g) $\mathrm{PC}: \mathrm{GL}=3: 7600$ times

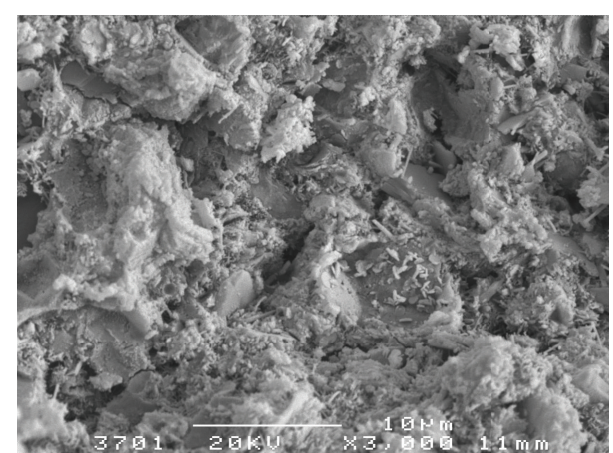

(b) PC 3000 times

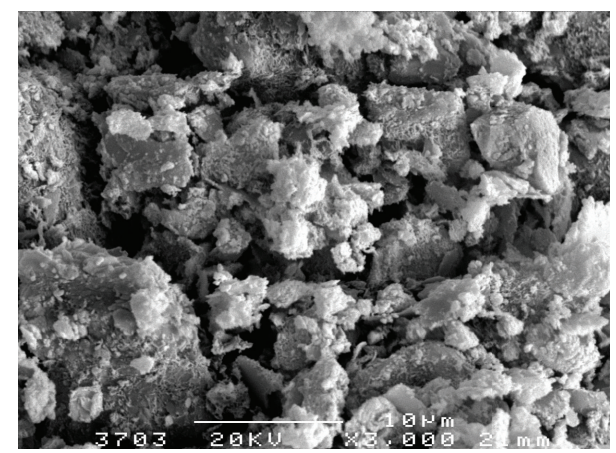

(d) PC:FAL $=1: 93000$ times

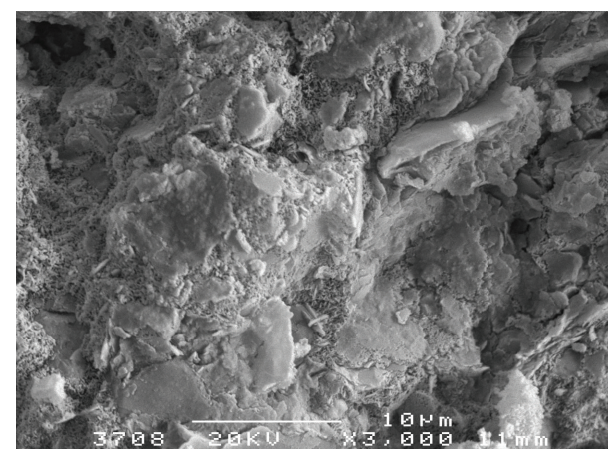

(f) $\mathrm{PC}: \mathrm{FAL}=3: 73000$ times

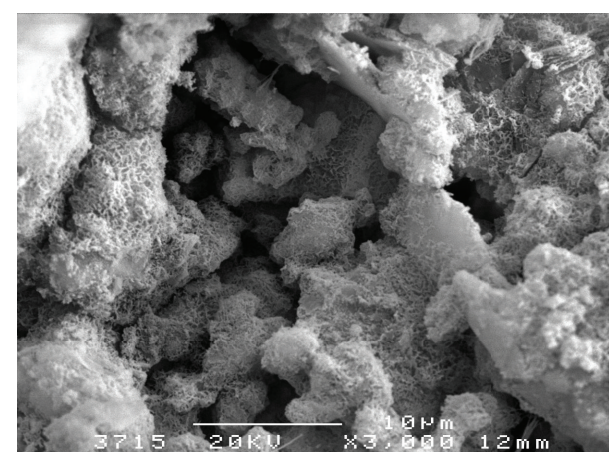

(h) PC: GL $=3: 73000$ times

FigURE 8: Scanning electron micrograph of $25 \%$ binder stabilized clay at 28 days. 


\section{Conclusions}

Fly ash reached lower permeability of stabilized soils than GGBS, although they reached a similar strength range. There was an optimum PC:FAL ratio for yielding the lowest permeability of stabilized soil at the same binder content and curing age, and this value was generally in a range of $2: 8-$ $4: 6$, varying with binder content and curing time. The 28 day permeability value of the PC mixes was 40 times that of corresponding optimum PFLC mixes, much higher at the same binder content. The microstructural analysis showed the CSH/CASH was produced during the fly ash hydration activated by Lime, although the main hydration production of the PC-fly ash-Lime stabilized soils were similar to those of PC.

\section{Conflict of Interests}

The authors declare that there is no conflict of interests regarding the publication of this paper.

\section{Acknowledgments}

This work is supported by The National Natural Science Foundation of China (Grant no. 41330641) and "Twelfth FiveYear" National Technology Support Program of China (Grant no. 2012BAJ01B02-01).

\section{References}

[1] G. Holm, "State of practice in dry deep mixing methods," in Proceedings of the 3rd International Conference on Grouting and Ground Treatment, pp. 145-163, ASCE, New Orleans, La, USA, February 2003.

[2] M. Terashi, "The state of practice in deep mixing methods," in Proceedings of the 3rd International Conference on Grouting and Ground Treatment, pp. 25-49, ASCE, New Orleans, La, USA, 2003.

[3] D. A. Bruce, "Practitioner's guide to the deep mixing method," Ground Improvement, vol. 5, no. 3, pp. 95-100, 2001.

[4] M. Kitazume, H. Yamazaki, and T. Tsuchida, "Recent soil admixturestabilization techniques for port and harbor constructions in Japan-Deep mixing method, premix method, light-weight method," in Proceedings of the International Seminar on Geotechnics in Kochi (ISGK'00), pp. 23-40, Kochi, Japan, 2000.

[5] E. A. Kehew, Geology for Engineers and Environmental Scientists, Prentice Hall, Englewood Cliffs, NJ, USA, 2nd edition, 1995.

[6] S.-D. Wang and K. L. Scrivener, "Hydration products of alkali activated slag cement," Cement and Concrete Research, vol. 25, no. 3, pp. 561-571, 1995.

[7] S. Song, D. Sohn, H. M. Jennings, and T. O. Mason, "Hydration of alkali-activated ground granulated blast furnace slag," Journal of Materials Science, vol. 35, no. 1, pp. 249-257, 2000.

[8] C. Shi, P. V. Krivenko, and D. Roy, Alkali-Activated Cements and Concretes, Taylor \& Francis, New York, NY, USA, 2006.

[9] T. P. Sherwood, Soil Stabilization with Cement and Lime: State of the Art Review, HMSO Books, London, UK, 1993.

[10] F. G. Bell, "Lime stabilization of clay minerals and soils," Engineering Geology, vol. 42, no. 4, pp. 223-237, 1996.
[11] T. M. Petry and D. N. Little, "Review of stabilization of clays and expansive soils in pavements and lightly loaded structureshistory, practice, and future," Journal of Materials in Civil Engineering, vol. 14, no. 6, pp. 447-460, 2002.

[12] M. P. Moseley and K. Kirsch, Ground Improvement, Spon Press, New York, NY, USA, 2nd edition, 2004.

[13] S. K. Dash and M. Hussain, "Lime stabilization of soils: reappraisal," Journal of Materials in Civil Engineering, vol. 24, no. 6, pp. 707-714, 2012.

[14] L. Lam, Y. L. Wong, and C. S. Poon, "Degree of hydration and gel/space ratio of high-volume fly ash/cement systems," Cement and Concrete Research, vol. 30, no. 5, pp. 747-756, 2000.

[15] D. T. T. Chang, W.-C. Lee, L.-L. Guo, and K. C. Yang, "Fly ash reducing the permeability of soil-cement mixture for the application of seepage cutoff," in Proceedings of the Geohunan International Conference, d 20110000, American Society of Civil Engineers, Hunan, China, June 2011.

[16] W.-H. Huang, "Properties of cement-fly ash grout admixed with bentonite, silica fume, or organic fiber," Cement and Concrete Research, vol. 27, no. 3, pp. 395-406, 1997.

[17] C.-Q. Jia, M.-S. Huang, and H. Yao, "Experimental research on stabilization of soft soil with cement and fly-ash in the Minjiang estuary," Journal of Tongji University, vol. 32, no. 7, pp. 884-888, 2004.

[18] M. H. Zhang, "Microstructure, crack propagation, and mechanical properties of cement pastes containing high volumes of fly ashes," Cement and Concrete Research, vol. 25, no. 6, pp. 11651178, 1995.

[19] W. A. Tasong, S. Wild, and R. J. D. Tilley, "Mechanisms by which ground granulated blastfurnace slag prevents sulphate attack of lime-stabilized kaolinite," Cement and Concrete Research, vol. 29, no. 7, pp. 975-982, 1999.

[20] S. Wild, J. M. Kinuthia, G. I. Jones, and D. D. Higgins, "Effects of partial substitution of lime with ground granulated blast furnace slag (GGBS) on the strength properties of limestabilised sulphate-bearing clay soils," Engineering Geology, vol. 51, no. 1, pp. 37-53, 1998.

[21] S. Wild, J. M. Kinuthia, G. I. Jones, and D. D. Higgins, "Suppression of swelling associated with ettringite formation in lime stabilized sulphate bearing clay soils by partial substitution of lime with ground granulated blastfurnace slag (GGBS)," Engineering Geology, vol. 51, no. 4, pp. 257-277, 1999.

[22] D. E. Macphee, M. Atkins, and P. P. Glassar, "Phase development and pore solution chemistry in ageing blast furnace slagPortland cement blends," in 12th Scientific Basis for Nuclear Waste Management, vol. 127 of MRS Proceedings, Cambridge University Press, 1988.

[23] American Society for Testing and Materials, ASTM D248711 Standard Practice for Classification of Soils for Engineering Purposes (Unified Soil Classification System), ASTM, West Conshohocken, Pa, USA, 2011.

[24] Y. Yi, M. Liska, and A. Al-Tabbaa, "Properties of two model soils stabilized with different blends and contents of GGBS, MgO, lime, and PC," Journal of Materials in Civil Engineering, vol. 26, no. 2, pp. 267-274, 2014.

[25] S. Y. Liu, G. C. Qian, and D. W. Zhang, The Principle and Application of Dry Jet Mixing Composite Foundation, Architecture Building Press, Beijing, China, 2006, (Chinese).

[26] N. Miura, S. Horpibulsuk, and T. S. Nagaraj, "Engineering behavior of cement stabilized clay at high water content," Soils and Foundations, vol. 41, no. 5, pp. 33-45, 2001. 
[27] S. Horpibulsuk, N. Miura, and D. T. Bergado, "Undrained shear behavior of cement admixed clay at high water content," Journal of Geotechnical and Geoenvironmental Engineering, vol. 130, no. 10, pp. 1096-1105, 2004.

[28] S. Horpibulsuk, N. Miura, and T. S. Nagaraj, "Claywater/cement ratio identity for cement admixed soft clays," Journal of Geotechnical and Geoenvironmental Engineering, vol. 131, no. 2, pp. 187-192, 2005.

[29] S. Horpibulsk, R. Rachan, A. Suddeepong, and A. Chinkulkijniwat, "Strength development in cement admixed bangkok clay: laboratory and field investigations," Soils and Foundations, vol. 51, no. 2, pp. 239-251, 2011.

[30] American Society for Testing and Materials, "Standard method for compressive strength of moldedsoil-cement cylinders," ASTM D1633-00, ASTM International, West Conshohocken, Pa, USA, 2007.

[31] American Society for Testing and Materials, "Standard test methods for measurement of hydraulic conductivity of saturated porous materials using a flexible wall permeameter," ASTM D5084, ASTM International, West Conshohocken, Pa, USA, 2003.

[32] E. W. Washburn, "Note on a method of determining the distribution of pore sizes in a porous material," Proceedings of the National Academy of Sciences of the United States of America, vol. 7, no. 4, pp. 115-116, 1921.

[33] S. Diamond, "Pore size distributions in clays," Clays and Clay Minerals, vol. 18, no. 1, pp. 7-23, 1970.

[34] D. Penumadu and J. Dean, "Compressibility effect in evaluating the pore-size distribution of kaolin clay using mercury intrusion porosimetry," Canadian Geotechnical Journal, vol. 37, no. 2, pp. 393-405, 2000.

[35] E. Romero and P. H. Simms, "Microstructure investigation in unsaturated soils: a review with special attention to contribution of mercury intrusion porosimetry and environmental scanning electron microscopy," Geotechnical and Geological Engineering, vol. 26, no. 6, pp. 705-727, 2008.

[36] A. A. Al-Rawas and A. McGown, "Microstructure of Omani expansive soils," Canadian Geotechnical Journal, vol. 36, no. 2, pp. 272-290, 1999.

[37] S. Horpibulsuk, N. Miura, and T. S. Nagaraj, "Assessment of strength development in cement-admixed high water content clays with Abrams' law as a basis," Geotechnique, vol. 53, no. 4, pp. 439-444, 2003.

[38] S. Horpibulsuk, R. Rachan, and A. Suddeepong, "Assessment of strength development in blended cement admixed Bangkok clay," Construction and Building Materials, vol. 25, no. 4, pp. 1521-1531, 2011.

[39] W. S. Wu, J. Zheng, and H. Gu, "Experimental study on the mechanics characteristics of cement-stabilized soft soil," Water Resources and Hydropower Engineering, vol. 29, no. 5, pp. 42-44, 1998.

[40] S. S. Chen, S. H. Song, J. L. Shen, and Y. Chen, "Experimental study on mechanical property of cement-stabilized dark soil in DJM pile," Chinese Journal of Geotechnical Engineering, vol. 23, no. 3, pp. 302-305, 2001.

[41] D. W. Zhang, L. B. Fan, S. Y. Liu, and Y. F. Deng, "Experimental investigation of unconfined compression strength and stiffness of cement treated salt-rich clay," Marine Georesources \& Geotechnology, vol. 31, no. 4, pp. 360-374, 2013.

[42] J. Asano, K. Ban, K. Azuma, and K. Takahashi, "Deep mixing method of soil stabilization using coal ash," in Proceedings of the 2nd International Conference on Ground Improvement Geosystems, Grouting and Deep Mixing, pp. 393-398, Tokyo, Japan, May 1996.

[43] S. Saitoh, Y. Suzuki, S. Nishioka, and R. Okumura, "Required strength of cement improved ground," in Proceedings of the 2nd International Conference on Ground Improvement Geosystems and Grouting and Deep Mixing, pp. 14-17, Tokyo, Japan, May 1996.

[44] A. Porbaha, S. Shibuya, and T. Kishida, "State of the art in deep mixing technology. Part III: geomaterial characterization," Proceedings of the ICE-Ground Improvement, vol. 4, no. 3, pp. 91-110, 2000.

[45] F.-H. Lee, Y. Lee, S.-H. Chew, and K.-Y. Yong, "Strength and modulus of marine clay-cement mixes," Journal of Geotechnical and Geoenvironmental Engineering, vol. 131, no. 2, pp. 178-186, 2005.

[46] G. A. Lorenzo and D. T. Bergado, "Fundamental characteristics of cement-admixed clay in deep mixing," Journal of Materials in Civil Engineering, vol. 18, no. 2, pp. 161-174, 2006.

[47] L. R. Hoyos, A. J. Puppala, and C. A. Ordonez, "Characterization of cement fiber treated reclaimed asphalt pavement aggregates: preliminary investigation," Journal of Materials in Civil Engineering, vol. 23, no. 7, pp. 977-989, 2011.

[48] T. W. Zhang, X. B. Yue, Y. F. Deng, D. W. Zhang, and S. Y. Liu, "Mechanical behaviour and micro-structure of cementstabilised marine clay with a metakaolin agent," Construction and Building Materials, vol. 73, pp. 51-57, 2014.

[49] S. Horpibulsuk, R. Rachan, and Y. Raksachon, "Role of fly ash on strength and microstructure development in blended cement stabilized silty clay," Soils and Foundations, vol. 49, no. 1, pp. 8598, 2009.

[50] S. Horpibulsuk, R. Rachan, A. Chinkulkijniwat, Y. Raksachon, and A. Suddeepong, "Analysis of strength development in cement-stabilized silty clay from microstructural considerations," Construction and Building Materials, vol. 24, no. 10, pp. 2011-2021, 2010.

[51] S. Kolias, V. Kasselouri-Rigopoulou, and A. Karahalios, "Stabilisation of clayey soils with high calcium fly ash and cement," Cement and Concrete Composites, vol. 27, no. 2, pp. 301-313, 2005. 

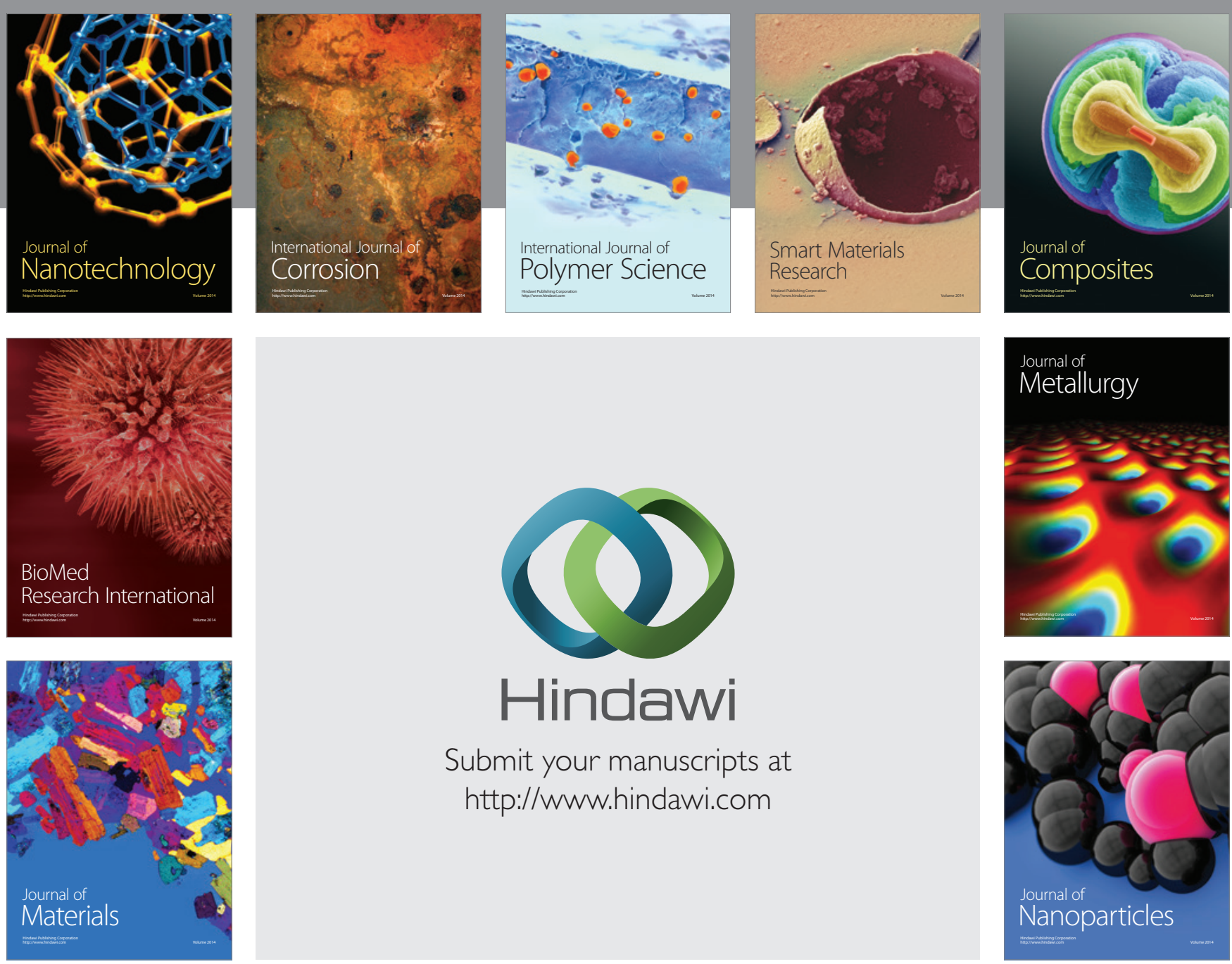

Submit your manuscripts at http://www.hindawi.com
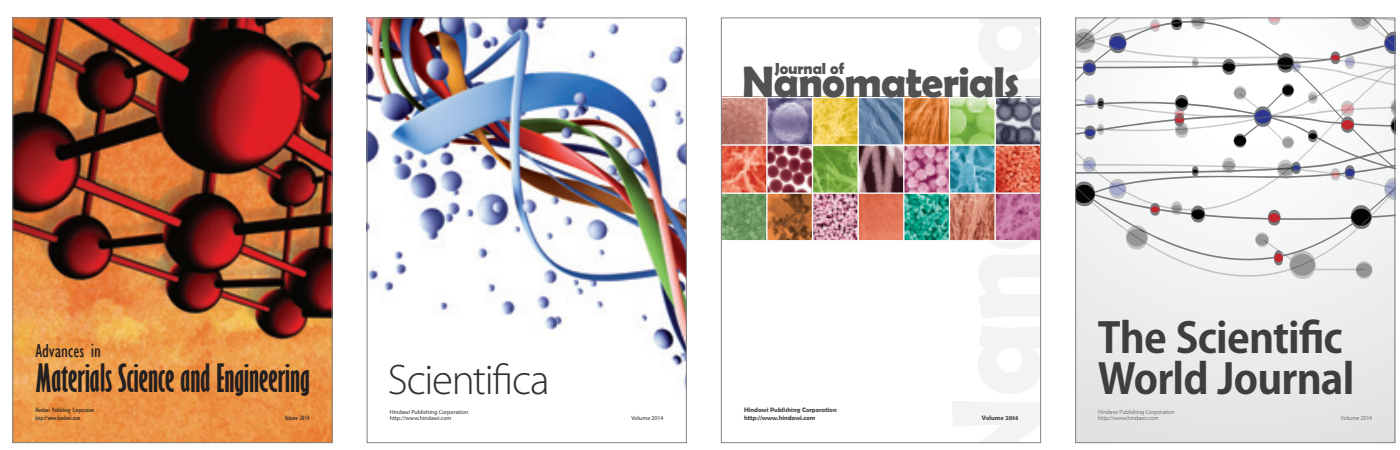

\section{The Scientific World Journal}
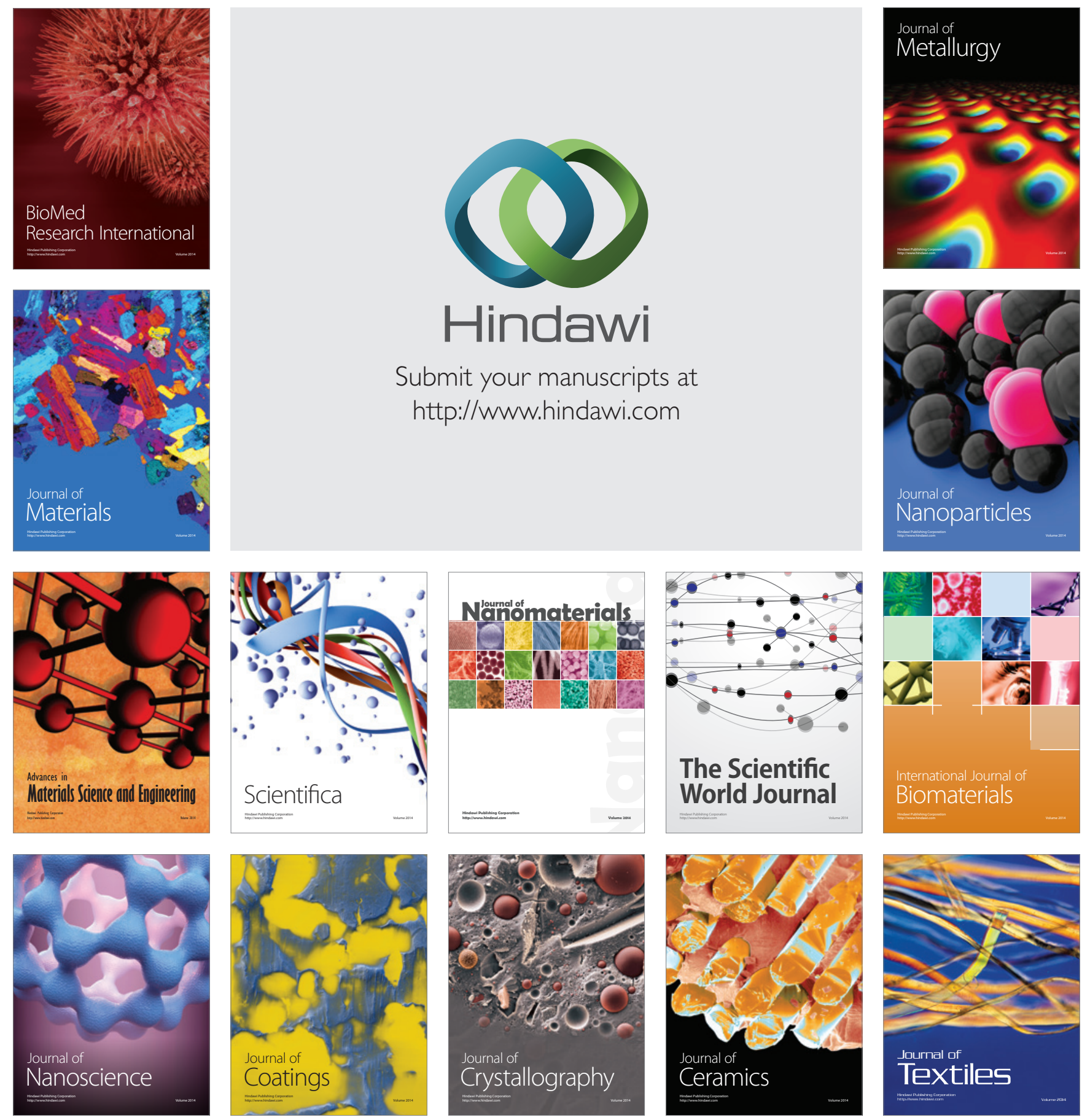